\title{
THE USE OF LEAN MANUFACTURING TECHNIQUES - SMED ANALYSIS TO OPTIMIZATION OF THE PRODUCTION PROCESS
}

\author{
Dusan Sabadka', Vieroslav Molnar ${ }^{2}$, Gabriel Fedorko² \\ 1 Technical University of Kosice, Faculty of Mechanical Engineering, Department of Automotive Production, \\ Masiarska 74, 04001 Kosice, Slovakia, e-mail: dusan.sabadka@tuke.sk \\ 2 Technical University of Kosice, Faculty of Mining, Ecology, Process Control and Geotechnology Logistics \\ Institute, Letna 9, 04200 Kosice, Slovak Republic, e-mail: gabriel.fedorko@tuke.sk; vieroslav.molnar@tuke.sk
}

Received: 2017.05 .15

Accepted: 2017.08.01

Published: 2017.09.03

\begin{abstract}
Lean is a culture of real and continuous optimization. As a concept of continuous optimization in the midst of limited resources, it must be practiced continuously as a long-term organizational norm. This paper revels why changeover time reduction is important in manufacturing industries and from the various tools and techniques available within Lean manufacturing describes mainly SMED (Single Minute Exchange of Dies) for changeover time reduction and its application in Shaft manufacturing industry. This paper also describes principles, benefits, procedures and practical application of SMED. Theoretical bases are verified in a practical part that describes the analysis and design optimization of non-productive time at changeover honing machine in a selected shaft manufacturing company. The output is the structural design of universal palettes and an evaluation of productivity due to optimization of operations of time honing gear shafts. The results achieved show considerable reduction in delay arising out of machine setting time, batch-setting time and demonstration delay.
\end{abstract}

Keywords: Lean manufacturing, SMED, changeover times.

\section{INTRODUCTION}

Lean Manufacturing is considered to be a waste reduction technique as suggested by many authors, but in practice lean manufacturing maximizes the value of the product through the minimization of waste [1]. Van Goubergen et al. [2] indicated three main reasons why set-up reduction initiatives can be appropriate for any company: to increase flexibility by conducting more changeovers and reducing lot size; to increase bottleneck capacities in order to maximize the line availability for production; and to minimize the cost, since production costs are related to equipment effectiveness.

According to Chiarini [3], the most important LM tools to eliminate the different kinds of waste in production are value stream map, cellu- lar manufacturing, total productive maintenance and single minutes Exchange of dies (SMED). A great amount of literature has addressed the first four tools [4], while information on SMED is a bit scarce.

SMED is a tool developed by Shingo [1] as a proposal to reduce bottlenecks caused by stamping presses in Toyota. By the time SMED was developed, the machines were not working at full capacity and, thus, were not bringing the expected benefites. Nowadays, as Utulas [5] points out, SMED is one of many LM tools for waste reduction in production processes, since it offers a fast and efficient way to decrease changeover times.

Single Minute Exchange of Dies (SMED)/ One-Touch exchange of Die (OTED) is systematic of the reduction of changeover time by converting possible internal setting time 
(Carry out during machine stoppage) to external time (performed while the equipment is running) and to simplify and streamline the remaining activity [1].

"Changeover times" is defined as the period between the last good product from previous production order leaving the machine and the first good product coming out from the following production order [6,7]. Changeover time is defined as the time needed to set up a given production system to run a different product with all the requirements $[8,18]$, and they are a typical example of waste, since changeover is a non-added value activity that incurs hidden costs [2]. Therefore, because machines remain inactive during changeover times, this process must be reduced as much as possible [8].

SMED is a practical LM tool that helps maximize the product value by reducing setup time and improves setup processes and provides a setup time reduction of up to $90 \%$ with moderate investments. Setup operation is the preparation or post adjustment that is performed once before and once after each lot is processed [1].

Shingo [1] bases his method on categorizing all setup activities into internal and external ones. With internal activities being ones that can only be performed when the machine is shut down, and external being those that can be conducted during the normal operation of the machine while it is still running. SMED methodology is formed by four single stages [1]; a preliminary stage where the internal and external set-up conditions are not distinguished; the first stage were separating internal and external set-up takes place; the second stage where internal activities are converted to external ones; and finally the third stage focusing on streamlining all aspects of the set-up operation.

Based on time/video study Shingo [1] separated the changeover $(\mathrm{C} / \mathrm{O})$ time into internal and external set-up time. The activities performed by stopping the machine are called internal set-up time and on the other hand when the activities are performed without stopping the machine, these activity are called external set-up time. Yamazumi chart is used to analyze the internal (online activity) and external (off-line) set-up time. Based on these analysis possible internal set-up time are converted to external set-up and internal set-up times are streamlined by introducing multi operator working parallel during On-line activity and one touch set-up adjustments to convert the $\mathrm{C} / \mathrm{O}$ time to single minutes.

\section{METHODOLOGY}

Optimization means reducing the production process time as much as possible to increase production productivity $[9,19]$. The main task is therefore to analyze the individual times of the operation of the production process, to find the time that most affects the length of the rebuilding and to find ways to reduce it. As these times are divided into production and non-productive, respectively. Productive and unproductive times, we focus mainly on non-productive production time.

As mentioned above, according to several authors $[1,2,3,8]$ SMED is a method for shortening the time of rebuilding production facilities. We minimize waiting times in a systematic process. For example workspace preparation, between the processing of two successive different types of production batches or products. For example, this method is about shortening the time for mold replacement, machine tool or production line rebuilding $[9,14]$.

The whole SMED method is based on a very thorough analysis of the redevelopment that we usually perform by direct observation at the workplace. Radically shortening conversion times from several hours to several minutes can be achieved, for example, in these ways:

- Classification and categorization of all redevelopment activities,

- Changing the organization of the reconstruction,

- Standardizing the conversion process,

- The training of each worker who performs the redevelopment,

- Special devices,

- Technical modifications of the machine [1].

This method is used in workplaces that are narrow where we often carry out rebuilding and the times required for rebuilding can result in significant losses of line capacity or machine capacity $[10,11,19]$.

The condition for the application of small production batches are short conversion times, which ensure short product lead times. Large production batches result in long lead times and high production progress. Reducing conversion times is a major factor in reducing doses [12]. Fig. 1 presents the expected improvement on changeover time depending on the different focus that can be adopted during the SMED implementation. If focus is only on methodology, results can be poor. In contrast, by combining design 


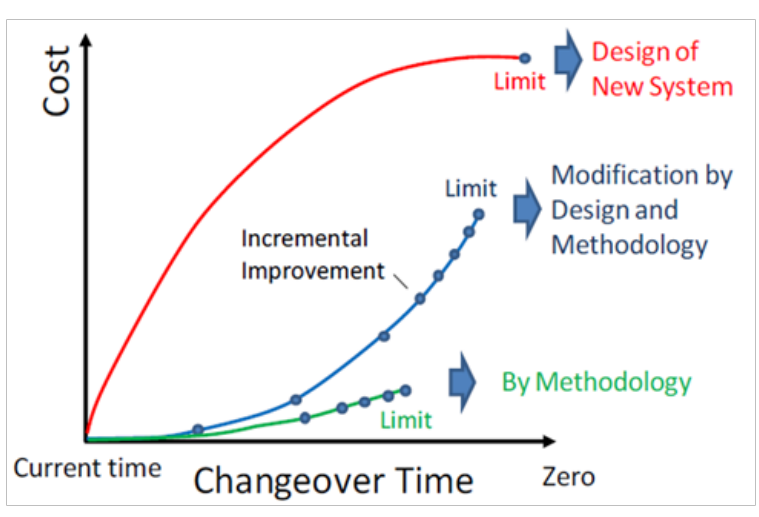

Fig. 1. Limits and costs of changeover improvement strategies [9]

modifications and methodology improvements, the outcomes can be acceptable with moderate investment $[12,18]$.

A long time for rebuilding also creates problems such as increased waiting times for processing or consuming critical capacities with regard to dose waiting [9].

The optimization project was implemented in a selected engineering company focusing on the production of gears. The SMED analysis tool was used to solve the optimization of the times that entered the production process of honing. SMED analyzes individual redevelopment times that represent the unproductive time of honing selected toothed shafts. Among the factors that directly affect the production process of honing in terms of productivity features [13]:
- input raw material - untreated shaft,

- machine technical options - machining parameters,

- tool - honing wheel (depends on the hardness of the disc).

Among the factors that indirectly influence the process of honing in terms of productivity features $[2,20]$ :

- reconstruction - derivative change,

- dose size - frequent reorgani zation of derivative changes,

- operator - experience,

- technical condition of the machine - malfunction.

After the set up of an SMED team, a video recording of the machine's manufacturing process (from the $\mathrm{H} 3$ shaft to the $\mathrm{H} 2$ shaft) was made, based on which the individual operations of the redevelopment were analyzed and included in the individual categories and the specified times of the individual operations.

The basic categories of redevelopment operations are: Clapmping, Cleaning, Control panel, Dressing, Loading/material, Measuring, Honing Head, Automation, Setting/Adjustment, Teachning, Try out, Waiting, Walking, Searching.

SMED analysis results showed that the average rebuilding consists of 94 operations and its total average time is 1 hour and 19 seconds, representing a non-productive time to be reduced. Selected parts of SMED rebuilding analysis is presented in Figure 2. After merging the opera-

\begin{tabular}{|c|c|c|c|c|c|}
\hline \multirow[t]{2}{*}{ 0:25:00 } & \multirow[b]{2}{*}{73} & \multirow[b]{2}{*}{ the position of the portal loader } & \multirow[b]{2}{*}{1} & \multirow[b]{2}{*}{$0: 00: 27$} & \multirow[b]{2}{*}{ Control panel } \\
\hline & & & & & \\
\hline \multirow{2}{*}{$0: 26: 23$} & 74 & Replacement of the gripper feeder & 1 & 0:00:56 & Automation \\
\hline & 75 & Walking to the pallets & I & 0:00:12 & Walking \\
\hline $0: 26: 35$ & 76 & Palletizing, Exchange pallets & 1 & $0: 06: 52$ & Automation \\
\hline $0: 33: 27$ & 77 & Loading the pallet & $\mathrm{E}$ & 0:00:08 & Loading/material \\
\hline 0:33:35 & 78 & Loading pieces on pallets & 1 & $0: 00: 13$ & Leading/material \\
\hline 0:33:48 & 79 & Mask replacement & 1 & 0:00:53 & Automation \\
\hline 0:34:41 & 80 & Walking to the machine & I & 0:00:18 & Walking \\
\hline
\end{tabular}

Fig. 2. Selected part of table with SMED rebuilding analysis 
Table 1. Operations from the automation category

\begin{tabular}{|c|c|l|c|c|c|}
\hline $\begin{array}{c}\text { Elapsed } \\
\text { time }\end{array}$ & \multicolumn{2}{|c|}{ Rebuilding observation } & \multicolumn{2}{c|}{ Subsequent analysis } \\
\hline $\begin{array}{c}\text { 0:00:05 } \\
0: 18: 15\end{array}$ & number & \multicolumn{1}{|c|}{ description of operations } & I/E & duration & Cathegory \\
\cline { 2 - 6 } & 65 & Rollchecker Exchange & I & $0: 00: 29$ & Automation \\
\hline $0: 18: 44$ & 66 & $\begin{array}{l}\text { Replacement of the grippers on the revolver and } \\
\text { closing of the door }\end{array}$ & I & $0: 01: 52$ & Automation \\
\hline $0: 20: 51$ & 68 & Remove the dresing tool from the machine & I & $0: 00: 09$ & Automation \\
\hline $0: 21: 00$ & 69 & Securing the dresing tool in a box & $\mathrm{E}$ & $0: 00: 20$ & Automation \\
\hline $0: 21: 20$ & 70 & Securing the dresing tool head in a box & $\mathrm{E}$ & $0: 00: 30$ & Automation \\
\hline $0: 21: 50$ & 71 & Exchange of the grippers & $\mathrm{I}$ & $0: 02: 04$ & Automation \\
\hline $0: 23: 54$ & 72 & Establish and clampe the dresing tool & $\mathrm{I}$ & $0: 01: 06$ & Automation \\
\hline $0: 25: 27$ & 74 & Exchange the grippers on the feeder & $\mathrm{I}$ & $0: 00: 56$ & Automation \\
\hline $0: 26: 35$ & 76 & Remove pallets, exchange pallets & $\mathrm{I}$ & $0: 06: 52$ & Automation \\
\hline $0: 33: 48$ & 79 & Mask exchange & $\mathrm{I}$ & $0: 00: 53$ & Automation \\
\hline & & Total time & & $\mathbf{0} 15: 11$ & \\
\hline
\end{tabular}

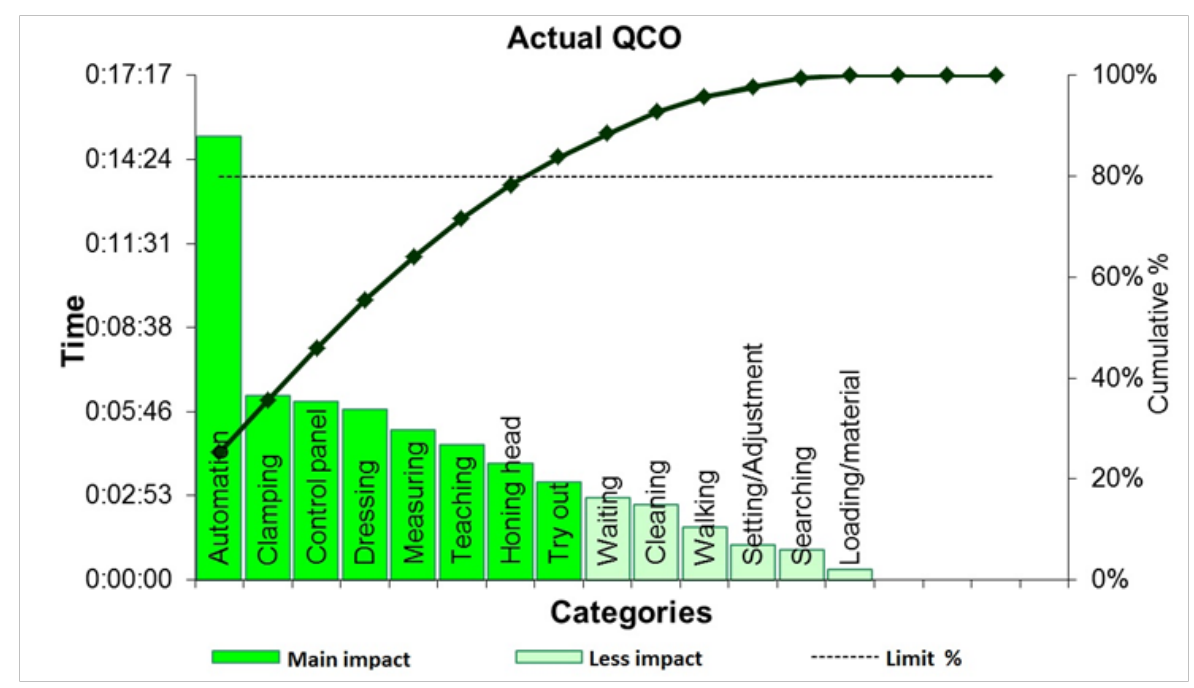

Fig. 3. Pareto graph

tions of each category into a separate table, the total times of these categories were then identified and the pareto graph created. Table 1 shows an operation from the automation category.

After adding the total time of the individual categories, a Pareto graph was drawn up (Fig. 3), which identified that the automation category had the greatest impact on the length of machine rebuilding and hence the productivity of the toothed shaft production.

In order to reduce the total time of this category, and thus reduce the total unproductive time in the gearing process, it was necessary to determine which operation is the longest and can be adjusted so that the total time drops to the lowest possible value. An analysis of all operations in the automation category has shown that operation with order number 76 - „remove pallets, pallet exchange“ takes the longest, even from all the operations of the whole reconstruction. This operation time is 6 minutes 52 seconds.

\section{Optimizing operations - analysis of the current situation}

In order to optimize the aforementioned process of machine rebuilding of the selected operation or shortening of time, it was necessary to modify the preparations so that they do not have to be replaced and replaced at each conversion to individual types of gears. A toothed shaft is mounted on the assembly jig, which is then moved over the belt into the honing machine. At present, a different type of assembly jig is used 


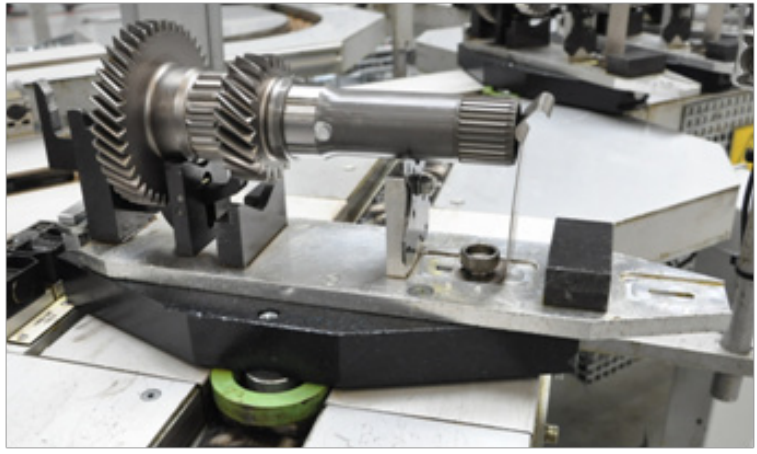

Fig. 4. Toothed shaft mounted on the pallet

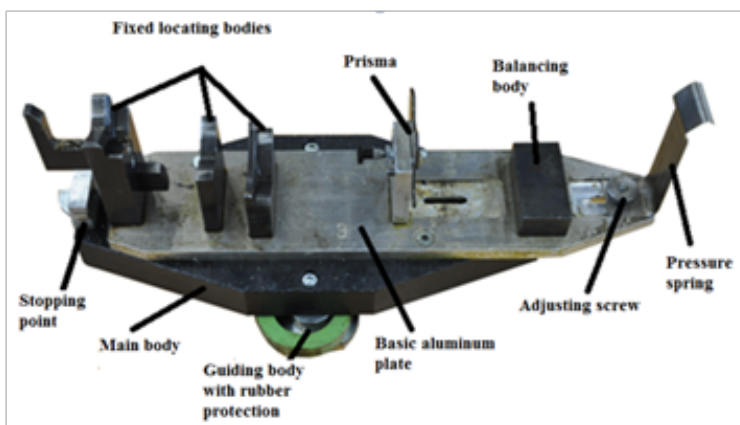

Fig. 5. Selected old pallet type

for each type of toothed shaft (5 types), resulting in increased conversion time. The goal of the optimization was to design a universal assembly jig for all 5 types of toothed shaft, replacing the current types (examples on Fig. 4 and Fig. 5).

\section{The starting conditions for the solution, design of the universal palette}

The task of the new assembly jig is to ensure that it is not necessary to exchange the prepara-

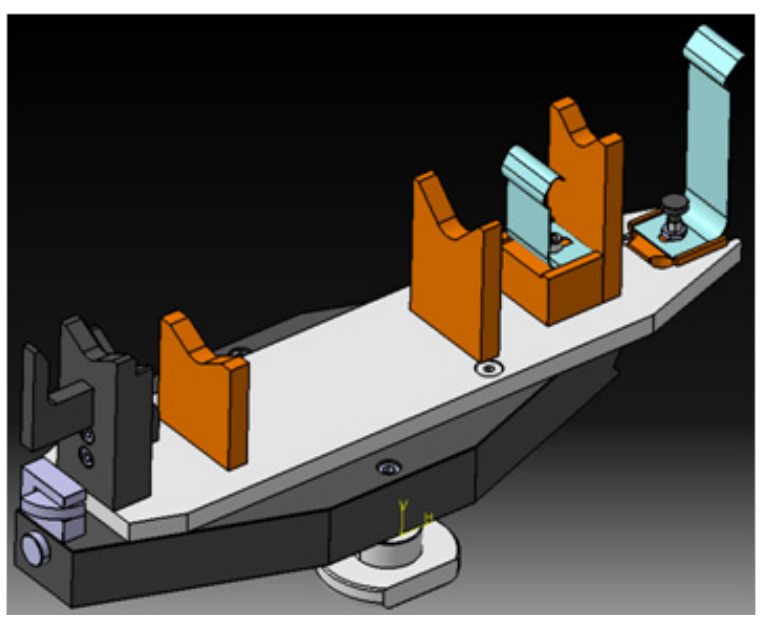

Fig. 6. 3D model of universal pallet for

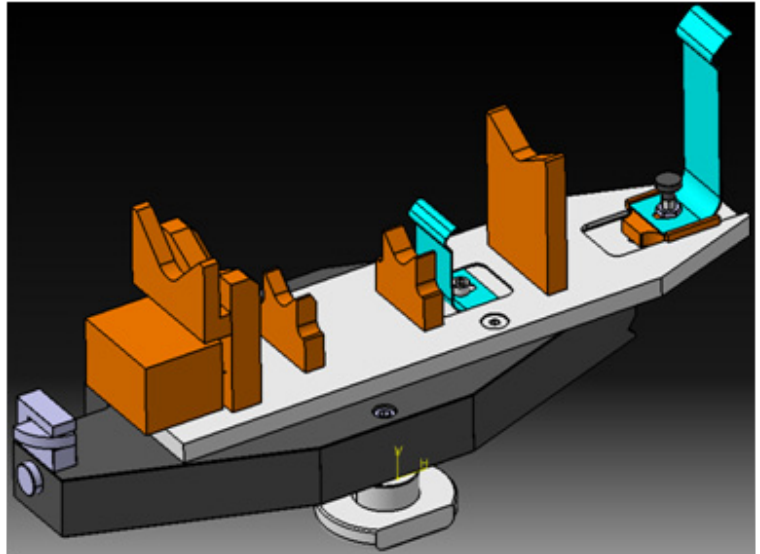

Fig. 7. 3D model of universal pallet for shaft shaft $\mathrm{H} 1, \mathrm{H} 2, \mathrm{H} 3, \mathrm{H} 4, \mathrm{H} 5$

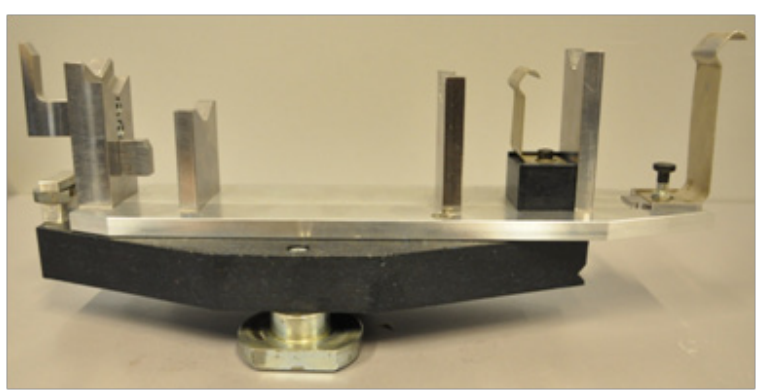

Fig. 8. Universal palette for shafts H1, H2

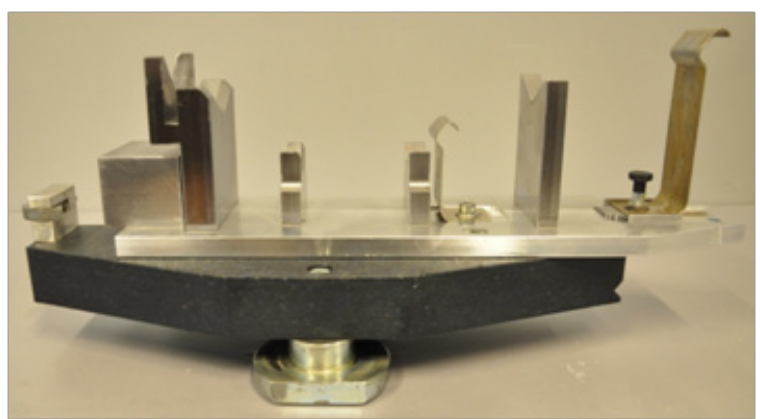

Fig. 9. Universal palette for shafts H3, H4, H5

tion in any machine rebuilding, and this has led to a reduction in unproductive time while eliminating the disadvantages of current pallets. Since the production process of honing takes place on four machines, two universal devices have been designed because of the very complex construction of only one. First - for input shafts marked H1 and $\mathrm{H} 2$, second - output shafts $\mathrm{H} 3, \mathrm{H} 4$ and $\mathrm{H} 5$ reverse gear. The CAD system with support for 3D modeling was used to create the design, namely the Catia V5 program with Part design modules, Assembly design, and Drafting. 
Table 2a. Preview of JPH Analysis for the 9th Week

\begin{tabular}{|c|c|c|c|c|c|c|c|c|c|c|c|c|}
\hline Reason/day & & Monday & & & Tuesday & & & enesda & & & Thursda & \\
\hline Work shift & A & $\mathrm{B}$ & $\mathrm{C}$ & A & B & $\mathrm{C}$ & $A$ & $B$ & $\mathrm{C}$ & A & $B$ & $\mathrm{C}$ \\
\hline $\mathrm{CHO}$ large-number & 2 & 0 & 0 & 2 & 3 & 2 & 0 & 0 & 0 & 0 & 1 & 1 \\
\hline $\mathrm{CHO}$ large-time & 2 & 0 & 0 & 2.5 & 4 & 2.5 & 0 & 0 & 0 & 0 & 1.15 & 1.25 \\
\hline $\mathrm{CHO}$ small-munber & 1 & 1 & 1 & 0 & 0 & 0 & 2 & 2 & 0 & 1 & 0 & 1 \\
\hline $\mathrm{CHO}$ small-time & 0.7 & 0.75 & 0.75 & 0 & 0 & 0 & 1.6 & 3.5 & 0 & 0.5 & 0 & 0.75 \\
\hline $\mathrm{CHO}$ total-number & 3 & 1 & 1 & 2 & 3 & 2 & 2 & 2 & 0 & 1 & 1 & 2 \\
\hline $\mathrm{CHO}$ total-time & 2.7 & 0.75 & 0.75 & 2.5 & 4 & 2.5 & 1.6 & 3.5 & 0 & 0.5 & 1.15 & 2 \\
\hline Maintenance & 1 & 0 & 0 & 0 & 0 & 0 & 2 & 2 & 4 & 1 & 7.5 & 3 \\
\hline Adjustment & 4 & 1.5 & 1.25 & 3.5 & 1.25 & 4 & 2.5 & 1.5 & 3.75 & 1 & 3 & 2.5 \\
\hline Profilling & 0 & 0 & 0.5 & 0 & 0 & 1 & 0 & 0 & 0 & 0 & 1 & 0 \\
\hline Clamps/Runout & 0.25 & 1 & 0.75 & 0.5 & 1 & 1.25 & 1 & 0.5 & 0.25 & 1 & 0.5 & 0 \\
\hline Rework & 0 & 0 & 0 & 0 & 0 & 0 & 0 & 0 & 0 & 0 & 0 & 0 \\
\hline Sercos & 0 & 0 & 0 & 0 & 1 & 0 & 0 & 3 & 0.5 & 0 & 0 & 0 \\
\hline $\begin{array}{l}\text { Maintenance } \\
\text { assistance. tests }\end{array}$ & 0 & 1.5 & 0 & 0 & 0 & 0 & 0 & 0.5 & 0 & 0 & 0 & 0 \\
\hline $\begin{array}{l}\text { Cleaning the } \\
\text { centrifuge }\end{array}$ & 0.5 & 0.25 & 0.25 & 0 & 0.25 & 1.25 & 0 & 0.25 & 0.25 & 0.25 & 0.25 & 0.25 \\
\hline $\begin{array}{l}\text { Unfulfilled cycle } \\
\text { time }\end{array}$ & 0 & 0 & 0 & 0 & 0 & 0 & 0 & 0 & 0 & 0 & 0 & 0 \\
\hline Waitting for parts & 0 & 4 & 0 & 3.5 & 2 & 1 & 5 & 0 & 0 & 1 & 0.75 & 2 \\
\hline Without operator & 0 & 0 & 7.5 & 0 & 0 & 4 & 0 & 0 & 4.5 & 6.5 & 0 & 4 \\
\hline Planned shutdown & 1 & 0 & 0 & 0.5 & 0 & 0 & 2 & 0 & 0 & 0 & 0 & 0 \\
\hline Losses (hours) & 9.45 & 9 & 11 & 10.5 & 9.5 & 14 & 14.1 & 11.25 & 13.25 & 11.25 & 14.15 & 13.75 \\
\hline $\begin{array}{l}\text { Losses of } \\
\text { machines (hours) }\end{array}$ & 8.45 & 5 & 3.5 & 6.5 & 7.5 & 9 & 7.1 & 11.25 & 8.75 & 3.75 & 13.4 & 7.75 \\
\hline Extra hours & & 7.5 & & & 7.5 & & & 7.5 & & & 7.5 & \\
\hline Effectiveness & $58.0 \%$ & $60.0 \%$ & $51.1 \%$ & $53.3 \%$ & $57.8 \%$ & $37.8 \%$ & $37.3 \%$ & $50.0 \%$ & $41.1 \%$ & $50.0 \%$ & $37.1 \%$ & $38.9 \%$ \\
\hline $\begin{array}{l}\text { Machine } \\
\text { effectiveness }\end{array}$ & $62.4 \%$ & $77.8 \%$ & $84.4 \%$ & $71.1 \%$ & $66.7 \%$ & $60.0 \%$ & $68.4 \%$ & $50.0 \%$ & $61.1 \%$ & $83.3 \%$ & $40.4 \%$ & $65.6 \%$ \\
\hline \multirow{2}{*}{$\begin{array}{l}\text { Number of } \\
\text { machines }\end{array}$} & A & $\mathrm{B}$ & C & \multicolumn{3}{|c|}{ Number of days } & \multicolumn{4}{|c|}{ Working time } & \multirow{2}{*}{\multicolumn{2}{|c|}{$\frac{\text { Number of shifts }}{15}$}} \\
\hline & 3 & 2 & 3 & 5 & 5 & 5 & 112.5 & 105 & 112.5 & 352.5 & & \\
\hline
\end{tabular}

Table 2b. Preview of JPH Analysis for the 9th Week

\begin{tabular}{|c|c|c|c|c|c|c|c|c|c|c|c|c|}
\hline \multicolumn{3}{|c|}{ Friday } & \multirow{2}{*}{ Saturday } & \multirow{2}{*}{ Sunday } & \multicolumn{8}{|c|}{ Total } \\
\hline A & B & C & & & \multicolumn{2}{|c|}{ A } & \multicolumn{2}{|c|}{ B } & \multicolumn{2}{|c|}{ C } & \multicolumn{2}{|c|}{ Total } \\
\hline 0 & 2 & 1 & 1 & 0 & \multicolumn{2}{|c|}{4} & \multicolumn{2}{|c|}{6} & \multicolumn{2}{|c|}{4} & \multicolumn{2}{|c|}{15} \\
\hline 0 & 5 & 1.75 & 1.5 & 0 & \multicolumn{2}{|c|}{4.5} & \multicolumn{2}{|c|}{10.15} & \multicolumn{2}{|c|}{5.5} & \multicolumn{2}{|c|}{21.65} \\
\hline 1 & 0 & 0 & 0 & 0 & \multicolumn{2}{|c|}{5} & \multicolumn{2}{|c|}{3} & \multicolumn{2}{|c|}{2} & \multicolumn{2}{|c|}{10} \\
\hline 1 & 0 & 0 & 0 & 0 & \multicolumn{2}{|c|}{3.8} & \multicolumn{2}{|c|}{4.25} & \multicolumn{2}{|c|}{1.5} & \multicolumn{2}{|c|}{9.55} \\
\hline 1 & 2 & 1 & 1 & 0 & \multicolumn{2}{|c|}{9} & \multicolumn{2}{|c|}{9} & \multicolumn{2}{|c|}{6} & \multicolumn{2}{|c|}{25} \\
\hline 1 & 5 & 1.75 & 1.5 & 0 & \multicolumn{2}{|c|}{8.3} & & & & 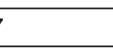 & & \\
\hline 0 & 0 & 2 & 0.5 & 0 & 4 & $3.56 \%$ & 9.5 & $9.05 \%$ & 9 & $8.00 \%$ & 23 & $6.52 \%$ \\
\hline 2 & 1.5 & 1 & 1 & 0 & 13 & $11.56 \%$ & 8.75 & $8.33 \%$ & 12.5 & $11.11 \%$ & 35.25 & $10.00 \%$ \\
\hline 0 & 0 & 0 & 0 & 0 & 0 & $0.00 \%$ & 1 & $0.95 \%$ & 1.5 & $1.33 \%$ & 2.5 & $0.71 \%$ \\
\hline 1 & 0.5 & 0 & 0.5 & 0 & 3.75 & $3.33 \%$ & 3.5 & $3.33 \%$ & 2.25 & $2.00 \%$ & 10 & $2.84 \%$ \\
\hline 0 & 0 & 0 & 0 & 0 & 0 & $0.00 \%$ & 0 & $0.00 \%$ & 0 & $0.00 \%$ & 0 & $0.00 \%$ \\
\hline 0 & 0 & 0 & 0 & 0 & 0 & $0.00 \%$ & 4 & $3.81 \%$ & 0.5 & $0.44 \%$ & 4.5 & $1.28 \%$ \\
\hline 0 & 0 & 0 & 0 & 0 & 0 & $0.00 \%$ & 2 & $1.90 \%$ & 0 & $0.00 \%$ & 2 & $0.57 \%$ \\
\hline 0.25 & 0.25 & 0.25 & 0.25 & 0 & 1 & $0.89 \%$ & 1.25 & $1.19 \%$ & 1.25 & $1.11 \%$ & 3.75 & $1.06 \%$ \\
\hline 0 & 0 & 0 & 1 & 0 & 0 & $0.00 \%$ & 0 & $0.00 \%$ & 0 & $0.00 \%$ & 1 & $0.28 \%$ \\
\hline 0 & 0 & 1.5 & 0 & 0 & 9.5 & $8.44 \%$ & 6.75 & $6.43 \%$ & 4.5 & $4.00 \%$ & 20.75 & $5.89 \%$ \\
\hline 8.5 & 0 & 7.5 & 2 & 0 & 15 & $13.33 \%$ & 0 & $0.00 \%$ & 27.5 & $24.44 \%$ & 44.5 & $12.62 \%$ \\
\hline 0 & 0 & 0 & 0 & 0 & 3.5 & $3.11 \%$ & 0 & $0.00 \%$ & 0 & $0.00 \%$ & 3.5 & $0.99 \%$ \\
\hline 12.75 & 7.25 & 14 & 6.75 & 0 & 58.05 & $51.6 \%$ & 51.6 & $48.7 \%$ & 66 & $58.7 \%$ & 181.95 & $51.6 \%$ \\
\hline 4.25 & 7.25 & 5 & 3.25 & 0 & 30.05 & $26.7 \%$ & 26.7 & $42.3 \%$ & 34 & $30.2 \%$ & 113.2 & $32.1 \%$ \\
\hline & & & 22.5 & & & & & & & & & \\
\hline $43.3 \%$ & $51.7 \%$ & $37.8 \%$ & $70.0 \%$ & $100.0 \%$ & & & & & & $3 \%$ & 52 & \\
\hline $81.1 \%$ & $51.7 \%$ & $77.8 \%$ & $85.6 \%$ & $100.0 \%$ & & & & & & $8 \%$ & 70 & \\
\hline $\begin{array}{l}\text { Num } \\
\text { mac }\end{array}$ & $\begin{array}{l}\text { oer of } \\
\text { hines }\end{array}$ & & erage tim & of a large & $\mathrm{CHO}(\mathrm{r}$ & & & & & 0 & & \\
\hline & 3 & & Average tin & ne of small & $\mathrm{CHO}(\mathrm{m}$ & & & & & 2 & & \\
\hline
\end{tabular}


The creation of 3D models of universal pallets was based on the requirements and dimensions of the individual shafts $[15,16,17]$. Fig. 6 and Fig. 7 illustrate the 3D models of the proposed universal pallets. Changes to the current type of pallets:

- the prisms have been replaced by fixed locating bodies on which the shaft is stored,

- a T-shaped groove has been formed in the base plate for displacing the compression spring on the body to provide a fixed position by means of a spring piston,

- creating new shapes of fixed stands.

After modeling all the components and creating in the Catia program, the individual pallet components were then manufactured with appropriate technologies and completed into prototypes (Fig. 8 and Fig. 9).

\section{RESULTS AND DISCUSSION}

From the results of the SMED analysis, the longest time to rebuild the honing machine is that of changing the assembly jig. By modifying or creating new universal pallet, a total of $6.87 \mathrm{~min}$ utes was saved on one rebuild. The time of one rebuild has therefore decreased from an average of 1.01 hours to 0.89 hours, which is a time optimization of $11.9 \%$.

Observed JPH (Job per Hour) analysis over the 9-week period revealed the following:

- the average number of conversions per week: 18 .

- average weekly rebuilding time: 1.01 hours $\mathrm{x}$

Table 3. Productivity of toothed shaft manufacturing

\begin{tabular}{|c|c|}
\hline Type of toothed shaft & pcs/hour \\
\hline Input shaft $\mathrm{H} 1$ & 73 \\
\hline Input shaft H2 & 72 \\
\hline Output shaft H3 & 75 \\
\hline Output shaft H4 & 73 \\
\hline Reverse shaft H5 & 89 \\
\hline Average number & 76.4 \\
\hline
\end{tabular}

$18=18.18$ hours.

- weekly rebuilding time after optimizing its time: 18.18 hours $-(18 \times 6.87 \mathrm{~min})=16.12$ hours.

- weekly saving time after optimizing of rebuilding time: 18.18 hours -16.12 hours $=$ 2.06 hours.

\section{Productivity evaluation}

Weekly production of toothed shafts produced on 3 machines at 18 changeover operations:

- 76,4 ks/hour $\times 3$ machines $\times(18 \times 8$ hours $)=$ 33004 pes.

Annual output at $100 \%$ machine efficiency:

- 33004 pcs x 46 weeks = 1518184 pcs/year.

Increase the productivity of toothed shaft production after optimizing the weekly rebuilding time:

- 76.4 pcs/hour x 2.06 hours $\doteq 157$ pcs.

Annual production after increased production productivity:

- $(33004$ pcs +157 pcs $)$ x 46 weeks $=1525406$ pcs/year.

By optimizing of time rebuilding honing machine was increased annual productivity gear shafts about 7222 units produced, an increase of $0.48 \%$.

\section{Taking account of the machine efficiency}

The efficiency of the machine influences the overall productivity of production and should therefore be taken into account when determining it. The following factors influence the efficiency of the machine: maintenance, adjustment outside of rebuilding, profiling, splinters / throwing, rework, sercos, maintenance assistance, tests, centrifuge cleaning, unfulfilled cycle time, part wait, no operator, scheduled outage.

From the JPH analysis, the average machine efficiency was $70 \%$.

Table 4. Comparison of productivity before and after optimization of time rebuilding

\begin{tabular}{|l|c|c|c|}
\hline & Before optimization & After optimization & Difference \\
\hline Average rebuilding time per week & 18.18 hours & 16.12 hours & $\mathbf{2 . 0 6}$ hours \\
\hline $\begin{array}{l}\text { Weekly production } \\
(100 \% \text { effectiveness })\end{array}$ & 33004 pcs & 33161 pcs & $\mathbf{1 5 7}$ pcs \\
\hline $\begin{array}{l}\text { Annual production } \\
(100 \% \text { effectiveness })\end{array}$ & 1518184 pcs & 1525406 pcs & $\mathbf{7 2 2 2}$ pcs \\
\hline $\begin{array}{l}\text { Annual production } \\
(70 \% \text { effectiveness })\end{array}$ & 1062729 pcs & 1067784 pcs & $\mathbf{5 0 5 5}$ pcs \\
\hline
\end{tabular}


The annual output of the production toothed shafts after optimization with respect to the efficiency of the machine:

- 7222 pcs/year x $70 \% \doteq 5055$ pcs/year.

\section{CONCLUSIONS}

Single Minute Exchange of Dies is systematic reduction of changeover time by converting possible internal setting time to external time and to simplify and streamline the remaining activity $[18,21]$.

The paper was dedicated to optimizing the timing of the shaft manufacturing operations in the selected company. The goal was to optimize the unproductive time of honing these shafts, thereby increasing production productivity.

Based on an analysis of the production process, it was found that productivity is most affected by non-productive activities that generate non-productive times. These are activities that are linked to the rebuilding of the honing machine. The unproductive time arises during the rebuilding of these machines to manufacturing of another type of shaft, so the analysis was aimed at optimizing the times of rebuilding.

For the analysis of the rebuilding the SMED tool was used, where every single operation was recorded by video. The rebuilding consists of a total of 94 operations and takes 1 hour and 19 seconds. Individual operations were categorized into 14 categories, showing that the automation category had the greatest impact on conversion.

There was selected operation no. 76 - pallet pallets, pallet exchange, which has the longest time not only in its category, but in all the operations of the entire rebuilding, lasting 6 minutes 52 seconds. This operation is best suited for optimization, due to the fact that all other operations are necessary and unchangeable. The optimization of this operation consisted in the construction design of new universal pallets, which need not be exchanged, whereas so far for each type of shaft used a different type of preparation. This saves the entire time of this operation, bringing the optimization of the time of this operation to $11.9 \%$.

After implementing changes in production, overall production of the shafts increased. Productivity evaluation and analysis was performed by monitoring the production process during a 9 week period, where the data were recorded and recorded in the JPH analysis, which showed that the average weekly rebuilding were 18 and thus 18.18 weekly unproductive.

Thanks to new universal pallets, this time is reduced by 2.06 hours. For this time it is possible to produce 157 pieces more. Annual production increases by $0.48 \%$, which is 7222 units by $100 \%$ machine efficiency. But since the efficiency of machines is $70 \%$, the overall increase in shafts ${ }^{6}$ productivity is 5055 units more than before.

\section{Acknowledgements}

This contribution is the result of the projects VEGA 1/0403/18, VEGA 1/0063/16, VEGA 1/0708/16, KEGA 018TUKE-4/2016.

\section{REFERENCES}

1. Shingo S. A revolution in manufacturing: The SMED system. Productivity Press, Stanford, CT. 1985

2. Goubergen D.V. and Landeghem H.V. Rules for integrating fast changeover capabilities into new equipment design. Robotics and Computer Integrated Manufacturing 18, 2002, 205-214.

3. Chiarini A. Sustainable manufacturing-greening processes using specific lean production tools: An empirical observation from European motorcycle component manufacturers. J. Clean. Prod. 2014, 226-233.

4. García-Alcaraz J.L., Maldonado-Macías A.A. and Cortes-Robles G. Lean Manufacturing in the Developing World: Methodology, Case Studies and Trends from Latin America; Springer: Cham, Switzerland, 2014, pp. 1-584.

5. Ulutas B. 2011. An application of SMED methodology. Int. Sch. Sci. Res. Innov. 2011, 1194-1197.

6. Gest G., Culley S.J., McIntosh R.I., Mileham A.R. and Owen G.W. Review of fast tool change systems. Computer Integrated Manufacturing Systems 8, 1995, 205-210.

7. Coimbra E.A. Total Flow Management: Achieving Excellence with Kaizen and Lean Supply Chains. Kaizen Institute. 2009

8. Sousa R.M., Lima R.M., Carvalho J.D. and Alves A.C. An industrial application of resource constrained scheduling for quick changeover. In Proceedings of the 2009 IEEE International Conference on Industrial Engineering and Engineering Management, Hong Kong, China, 8-11 December 2009, 189-193.

9. Cakmakci M. Process improvement: performance analysis of the setup time reduction SMED in the automobile industry. International Journal of Advanced Manufacturing Technology 41, 2009. 168-179. 
10. Wang J. Perspectives and Techniques for Improving Information Technology Project Managment. USA: Montclair State University, 2013.

11. McIntosh R.I., Culley S.J., Mileham A.R. and Owen G.W. Changeover improvement: A maintenance perspective. International Journal of Production Economics 73, 2001, 153-163.

12. Ferradás P.G. and Salonitis K. Improving changeover time: a tailored SMED approach for welding Cells. Forty Sixth CIRP Conference on Manufacturing Systems 2013. Procedia CIRP 7. 2013. 598 - 603.

13. Mrkvica I. Speciální technologie: Výroba ozubených kol II. Ostrava: VŠB-TU Ostrava, 1.vyd., 2009.

14. Jachowicz T.: Construction of clamping units of injection molding machines. Polimery 2005, 2 (50), $110-117 .$.

15. Madáč K., Durkáč V., Král' J. Design of applications for CAD system Creo Parametric 1.0. Int. Sci. Her., 4, 2012, 278-284.

16. Mantič M., Kul'ka J., Krajňák J., Kopas M., Schneider M. Influence of selected digitization methods on final accuracy of 3D model. In: Majerník, M., Daneshjo, N., and Bosák, M. (eds.) Produc- tion Management and Engineering Sciences. pp. 475-480. CRC Press Taylor and Francis Group A Balkema Book, 2016.

17. Debski H., Koszalka G., Ferdynus M. Application of FEM in the analysis of the structure of a trailer supporting frame with variable operation parameters. Eksploatacja i Niezawodnosc - Maintenance and Reliability, 14, 2012, 107-113.

18. Díaz-Reza J.R., García-Alcaraz J.L., MartínezLoya V., Blanco-Fernández J., Jiménez-Macías E. and Avelar-Sosa L. The Effect of SMED on Benefits Gained in Maquiladora Industry. Sustainability _ Open Access Journal 2016

19. Gregor M. and Mičieta B. Productivity and Innovations. Žilina: Slovenské centrum produktivity, 2010.

20. Vasilko K., Havrila M., Novák-Marcinčin J., Mádl J., Zajac J. Top trendy v obrábaní, III. Čast'- Technológia obrábania. Žilina. Media/ST, 2006.

21. Sundar R., Balaji A.N., SatheeshKumar R.M. A Review on Lean Manufacturing Implementation Techniques. 12th Global congress on manufacturing and management, gcmm 2014. Procedia Engineering 97, 2014, $1875-1885$. 